fessional education because of other life experiences.

These are a few ideas, meant to instigate a more thorough, thoughtful examination. Major changes in training are hard for individual schools to implement unilaterally, because undergraduate medical education, residency, and fellowships are overseen by different accreditation organizations that have different perspectives and goals. But the time seems right for a national discussion, particularly following on a forwardlooking report that was recently released by a joint AAMC-HHMI expert committee (1). Describing competencies rather than courses needed by physicians of the future, this report could serve as a cornerstone for rethinking how we educate physicians.

As with health care reform in general, there will undoubtedly be trade-offs. A fresh look at medical education may expose what is bound to be one of many elephants in the crowded room of health care reform - students and their families pay large sums and assume heavy debt to obtain professional credentials to work in the service of society. The personal cost has been accepted in the United States until now, but there may be more pushback if either prestige or potential earnings are diminished. New models for financing the education of health care professionals may ultimately need to be on the table, too, as we think about better aligning incentives for a healthier population.

\section{Nancy C. Andrews}

Duke University School of Medicine, Durham, North Carolina, USA. E-mail: nancy. andrews@duke.edu.

J. Clin. Invest. 119:2860-2861 (2009). doi:10.1172/JCI41105.

1. AAMC-HHMI Scientific Foundations for Future Physicians Committee. 2009. Scientific foundations for future physicians. Association of American Medical Colleges/Howard Hughes Medical Institute. Washington, DC, USA. 46 pp.

\title{
A view from a European medical academic who spends time in the US
}

\begin{abstract}
A merican medicine has much to be proud of. Since World War II, the National Institutes of Health has sparked a revolution in academic biomedical research. There are world-leading academic hospitals delivering the best-quality health care, such as Johns Hopkins, the Mayo Clinic, Mass General, and the Hospital for Special Surgery, among others. Cancer care and outcomes are the world's best. But there are also problems on a huge scale, which means that the US's world-leading health expenditure ( $16 \%$ of GNP) is delivering health care that is worse than in much of Europe in terms of clearly analyzable indicators, such as infant mortality or length of life. European countries like the UK typically spend $8 \%-10 \%$ of GNP on health care. But that is not to say that European or British medical care doesn't have its own problems, as certain aspects - such as the UK's cancer survival rates - are worse than in the US.

The lower-percentage cost of health care in Europe covers all the population, while the US's $16 \%$ still leaves 45 million uncovered. Clearly there is an unanswerable case for major reform in order to deliver value for money, not just for the lucky ones able to avail themselves of the best hospitals, or of quality cancer care, but for all the population. The humanitarian principle - quality health care for all - that the European nations have espoused, though practised in different ways, leaves none of the population disadvantaged and uncovered.
\end{abstract}

The $16 \%$ of GNP spent on health care in the US is having dire economic consequences. That each of Detroit's US car manufacturers' vehicles allegedly has about $\$ 1,000$ of health care costs in its price is hard to comprehend, but its consequences are apparent. Costs of $16 \%$ and rising are clearly unsustainable. That most personal bankruptcies in the US are due to health care costs is also amazing. From a distance some of the causes of the cost differences of the US and European systems can be seen. Three are worth highlighting. The greater litigiousness of the US has led to "defensive medicine," with its unnecessary tests and treatment. This requires reform of the medico-legal interface to avoid blaming physicians for unfortunate but unpredictable events. Reducing claims and medical insurance costs would help reduce the total cost of health care. The culture of health insurers trying to make a profit from delivering health insurance is another problem that has been well documented; they cut costs by excluding coverage and care and having plans whose coverage is very difficult to understand. Wendell Potter, the Senior Fellow on Health Care for the Center for Media and Democracy, in his testimony to the US Senate Committee has clearly documented this problem (1). A controversial issue is the appropriateness of intensive care for late-stage terminally ill patients with no hope of recovery, with the Terri Schiavo case as a most dramatic example (2). Americans pay a huge cost for health care, and some estimate that half of lifetime medical costs occur in the last year of life; far more patients with terminal illness die after weeks in intensive care in US than Europe.

Having been in the US on holiday recently (August 2009), I saw some of the televised town hall debates. It is sad to see firsthand the misinformation and misunderstanding of many angry participants, frightened of change, frightened of losing benefits, frightened of "socialized" medicine like Britain's National Health Service (NHS), while not realizing what a poor deal they actually have from the current system, compared to their European and Canadian cousins.

The degree of misinformation is clearly illustrated by fears that chronic disease patients would be left to die. It was said by Investor's Business Daily in July 2009 that prominent scientist Professor Stephen Hawking (with Lou Gehrig's disease) would be left to die by socialized medicine in the UK's NHS (3). This sadly reflects the gross politicization of this debate. Hawking, as is well known, lives in the UK and has been kept alive for an amazingly long time by the care and devotion of the NHS. Enough said.

It is not appreciated by many that health care for the uninsured in the US is still paid for, by cross-subsidies. Instead of receiving lower-cost routine care from primary care physicians early in the disease process, these patients will eventually turn up when much more ill in the emergency rooms and 
then get very expensive care, costs that the hospitals recoup by averaging out over all their other, insured customers.

So there are plenty of problems to be solved. Perhaps the first step toward solving them is for an appreciation that there are proven ways of delivering health care that is both cheaper and better for most of the population than the current style in the US. There is no need to look across the Atlantic, where cultures are different. Just look closer, north, to Canada. The

am often asked what is the single most important issue that needs to be resolved in order to insure that health care reform moves forward in America. The answer is actually quite simple. If the key reason to reform the health care system is to extend health insurance coverage to the tens of millions of Americans who have none, then all those promoting reform but especially President Obama must drive home the ethical position that health care is a right.

As the current debate over health reform shows, those who oppose change argue that health reform cannot work because reform is not practical due to "the details." A larger load of baloney masquerading as an argument is hard to imagine.

Health reform is not in the details. Think I am wrong? How far did we get this summer wallowing around in claims about co-ops, public plans, death panels, rationing, and cost savings?

Health reform is in the ethics. It will only occur if those who favor it can win the fight to recognize a right to health care. If health care is recognized as a right, then the details of how to achieve affordable health insurance reform will follow. If it is not, then efforts to move reform forward will simply die under the weight of nitpicking, fearmongering, sloganeering, and the invocation of details as obstructions to change.

Only critics looking for some way to derail reform give a hoot about details. Details are the place reform goes to die. No one at a town meeting or in Congress was ever motivated to worry about health reform solely by getting the details. If health care is not acknowledged as a right, then no amount of detail will ever move health reform forward.
Canadians are all insured, there are no health care bankruptcies, and they live longer than in the US.

There is a strong case for major reform: it should provide a win for health and a win for the economy.

\section{Marc Feldmann}

Imperial College London, London, United Kingdom. E-mail: m.feldmann@imperial. ac.uk.

\section{Right to reform}

No nation on earth has ever reformed its health care system by asking the public to wallow around in the details of health reform. Canada, Britain, France, Spain, Singapore, Taiwan, Germany, Switzerland, Australia, New Zealand, and the rest of the list of our economic peer nations that have universal health care coverage did not assemble their finest numbers crunchers and pencil pushers and send

\section{The physician's voice}

Health reform is not in the details. Think I

am wrong? How far did we get this summer wallowing around in claims about co-ops, public plans, death panels, rationing, and cost savings? Health reform is in the ethics.

them into the front lines of the battle to sell reform. Each nation secured agreement that health care is a right and then and only then moved on to figure out how to guarantee that right to all citizens.

In some societies, health care is seen as a right because it has been earned. The British National Health Service was created in response to the British public having endured the Nazi blitz for many awful years. Some societies see health care as a right because a healthy workforce means a stronger economy. That was the basis for health care reform in Germany and Singapore. And in some nations, health care is seen as a right because of the ethical belief that a community should look after its own. Switzerland, Canada, Australia, France, Taiwan, New Zealand, and many other nations have grounded their right to health care in this idea of social solidarity.
J. Clin. Invest. 119:2861-2862 (2009). doi:10.1172/JCI41024.

1. US Senate. Committee on Commerce, Science, and Transportation. Consumer choices and transparency in the health insurance industry: hearing before the committee on commerce, science, and transportation. 111th Cong., 1st sess., June 24, 2009. (statement of W. Potter)

2. Terri Schiavo case. Wikipedia. http://en.wikipedia. org/wiki/Terri_Schiavo_case.

3. 2009 August 12. Bloggers debate British healthcare. BBC. http://news.bbc.co.uk/1/hi/world/americas/ 8198084.stm

America is not likely to buy any of these arguments. But there is a foundation for rights that every American understands - equality of opportunity.

Our nation loves the free market. But you cannot compete in the free market unless you can see, hear, move, chew, think, communicate, and breathe. Health care is essential to being able to do these things. We must make sure that each one of us has minimal insurance coverage so every one can compete and flourish in a free society if we are really a nation that takes equality of opportunity seriously. Once that commitment is made, then and only then do the details become important, because then and only then are arguments over the details carried out in good faith to try and achieve the agreed-upon goal of expanding health insurance coverage.

True, access to health care and having health insurance are not the same thing. But without universal basic health insurance coverage, access to health care is sporadic, inefficient, and hugely expensive. The road to health reform goes right through the acknowledgement that health care is a right. Those favoring reform need to say so and need to understand the basis for why it is true. Those who oppose reform should have to answer why they believe health care is not a right rather then using a false concern about the details to bog reform down.

\section{Arthur L. Caplan}

University of Pennsylvania, Philadelphia, Pennsylvania, USA. E-mail: caplan@mail. med.upenn.edu.

J. Clin. Invest. 119:2862 (2009). doi:10.1172/ JCI40987. 